\title{
La novedad teológica de la filosofía de Zubiri
}

\author{
Antonio González, \\ Centro de Reflexión Teológica, \\ San Salvador.
}

Xavier Zubiri dividía la exposición de lo que él denominaba "cl problema teologal del hombre" en tres grandes apartados. En primer lugar, Zubiri abordaba el análisis filosófico del problema de Dios. Es justamente lo que está recogido en el libro póstumamente publicado sobre El hombre y Dios'. En segundo lugar, Zubiri acometía el estudio, también filosófico, de la historia de las religiones. Se trata de inéditos procedentes de tres cursos orales de los años sesenta y setenta, que se han publicado recientemente en un nuevo tomo de inéditos sobre El problema filosofico de la historia de las religiones (cfr. HR). Finalmente tenemos un grupo amplio de tex los de la misma época en los que Zubiri aborda el estudio del Cristianismo como religión de "deiformación". Aunque en las dos primeras partes no escasean las referencias a cuestiones teológicas, esta última es la que trata sistemáticamente los grandes temas de la teología. Por eso podemos referimos a ellos, aunque sea en primera aproximación, como los "escritos teológicos" de Zubiri. La pregunta a la que aquí queremos responder es la del significado que tales escritos pueden tener para la teología actual.

No faltan en la creciente bibliografía sobre Zubiri los estudios de su teología. Prescindiendo de alusiones ocasionales hay que decir que la mayor pare de los análisis se concentran en arículos escritos por Zubiri en los años treinta o cuarenta, y especialmente en su trabajos sobre "El ser sobrenatural: Dios y la deificación en la teologla paulina", recogido en Naturaleza, historia, Dios (cfr. NHD 455-542). Aunque Zubiri insistía al comienzo de aquellas páginas en que no pretendla hacer más que un estudio histórico, no cabe duda que la exposición de la teología de Pablo y de los padres griegos dejaba traslucir muchas inclinaciones teológicas del propio Zubiri, como los cursos y escritos posteriores confirman. El mencionado arúculo posee, sin duda, un gran valor histórico y teologico. Sin embargo, no puede ser tomado ni como el exponente definitivo de las opiniones teológicas de Zubiri ni tampoco como criterio para valorar las con- 
secuencias teológicas de su filosofía. La razón es obvia: la filosofía de Zubiri estaba entonces aún sin elaborar, y sólo desde su filosolia madura es posible determinar la relevancia teológica de la misma.

Con esto ya queda enunciado un problema importante para nuestro tema, que es el de determinar cuál es la filosofía madura de Zubiri. Es algo que desborda el marco de estas páginas. No obstante, y sin entrar en discusiones sobre cronologías, es un hecho aceptado por todos que la filosofía de Zubiri no ha dejado de "madurar" hasta su úlima obra sobre la Inteligencia sentiente (cfr. IRE, IL, IRA). Los inéditos sobre ternas teológicos, procedentes de cursos orales imparidos en los años sesenta y principio de los setenta, son anteriores a la obra última de Zubiri. Es obvio sospechar que, desde esta última obra, muchos de los temas ratados en los escritos teológicos tendrían un aspecto considerablemente distinto. Esto es algo que se puede confirmar lácilmente comparando el contenido de estos escritos con las referencias a temas teológicos en otros textos posteriores. El caso más claro se presenta en las "Reflexiones teológicas sobre la eucaristia" (cfr. RTE), un trabajo escrito por Zubiri en 1981 que muestra diferencias notables con el tratamiento del tema la eucaristía en los mencionados cursos.

Esto no mengua la relevancia teológica de la filosofía de Zubiri. Solamente se está diciendo que esta relevancia no hay que buscarla exclusivamente en sus estudios sobre problemas teológicos, sino más bien en la filosofía misma de Zubiri, considerándola desde el punto de vista de su última obra. Desde ella habría que leer y elaborar los escrilos de Zubiri sobre temas teológicos. Mencionemos solamente un ejemplo: mientras en el curso oral de 1971 la articulación entre la realidad sustantiva y el ser tiene un papel central en la concepuación de los problemas teológicos, el mencionado artículo de 1981 pone en primer plano la actualidad. Tanto es así, que el concepto de "transsustantivación" como explicación del misterio eucarístico deja paso al concepto de "Iransactualización". El concepto de acualidad, cada vez más presente en su obra, habrá de desempefíar probablemente un papel central a la hora de repensar, desde la filosofía última de Zubiri, sus rellexiones sobre otros problemas teológicos.

Sin duda hay en este campo una gran tarea por hacer, la cual precisa aún de la publicación de los escritos teológicos de Zubiri. Sin embargo, probablemente es equivocado pensar que la principal aportación de Zubiri a la teología consiste en la aplicación de los conceptos claves de su filosofía a determinados problemas teológicos. No cabe duda de que sólo con ello la contribución de Zubiri a la teología sería importante y novedosa. Piénsese por ejemplo en la relevancia que tendría para la teología moral una filosofía en la que no cabe hablar de ningún "derecho natural" (cfr. HR 87-88). O en la importancia de tratar el tema del pecado original fuera de la perspectiva naturalista en la que ha sido planteado (cfr. DHC 277-279). Ahora bien, tal vez el análisis de estas "aplicaciones" de la filosofía de Zubiri a problemas teológicos determinados puede hacemos perder de vista 
el sentido general de las relaciones entre la filosofía de Zubiri y la teología. Aunque en el afio 1967 Zubiri lodavía entendía su posible contribución a la teología en estos términos, en el af̃o 1971 Zubiri intenta ya una interpretación global del cristianismo. Esta interpretación global no es una mera suma de respuestas filosóficas a problemas concretos planteados por la teología, sino que incluye y supone una pregunta por las relaciones entre la filosolia de Zubiri, tomada en bloque, y la historia del pensamiento teológico.

\section{El problema filosófico de la teología europea}

En esla perspectiva, hay entonces que comenzar sertalando que la posición de la filosolía de Zubiri respecto de la teología comienza siendo enormemente crítica. Algunas referencias al pensamiento teológico de Zubiri pueden pasar por alto este hecho, que en realidad es esencial para entender el sentido y la intención última de muchas de sus renlexiones teológicas. En realidad, una exposición adecuada del pensamiento teológico de Zubiri tiene que empezar por señalar que, a los ojos de ésle, la teología cristiana ha tenido un efecto negativo sobre la historia del pensamiento filosófico. Es algo que Zubiri plantea ya en sus escritos juveniles y que puede seguir siendo afirmado desde la perspectiva de su filosolía madura. $Y$ es que, según Zubiri, á pesar de

todas sus limitaciones, la filosofía griega nació, por lo menos, de sí misma, frente a las cosas en inmediato contacto con ellas. Pero el hombre de la era cristiana no se encontró consigo mismo nunca de una manera inmediata, sino mediante Dios, es decir, con la mirada fija en el ente infinito (SPF II 117).

El resultado, según Zubiri, es que la filosofia europea, desde san Aguslín hasta Hegel

comienza siendo esencialmente teológica. Esto es, ha segregado el espíritu humano del universo para proyectarlo excéntricamente sobre la divinidad, sobre esa divinidad de quien nos decía el cuarto evangelio que es esencialmente lógos, verbo, palabra (NHD 274).

Ciertamente resuenan en estos reproches de Zubiri muchas de las críticas de los posthegelianos, y especialmente de Niezsche, a la teología cristianaz. La filosofía posthelénica, como el espiritu humano mismo, estaria excéntricamente vertida sobre la divinidad. En el caso de Zubiri, naturalmente, no se trata de una crítica del cristianismo ni de una crílica de la teología en cuanto tales, sino de una crítica de la función filosófica que la teologia ha desempeñado en occidente. Ciertamente, Zubiri siempre reconocerá al cristianismo el mérito de haber introducido en la historia del pensamiento, a raiz de las discusiones cristológicas de los primeros cuatro siglos, el concepto de persona (cfr. HD 323). Pero, como vamos a ver más detenidamente, esta contribución fundamental a la historia del pensamiento está empañada, a los ojos de Zubiri, por las consecuencias filosóficas de 
otro concepto de origen cristiano: la idea de una creación ex nihilo. En la raíz de ambas cuestiones estaría la identificación del lógos del cuarto evangelio con el lógos de la filosolia griega. Con ellos tenemos ya enunciados los tres grandes temas de nuestra exposición: la creación, la persona y el lógos.

\section{a) La creación desde la nada}

La creación desde la nada no es, para Zubiri, un nuevo concepto que enriquece el elenco de los anteriores. Se trata, más radicalmente, de un concepto que cambia el horizonte mismo del pensamiento, de tal manera que todos los conceptos griegos, y también el concepto mismo de persona, van a ser situados en un nuevo sistema de referencia. Mientras que los griegos se han preguntado por las cosas reales desde el punto de vista de su movilidad, el hombre europeo, desde Agustín hasta Hegel, considerará las cosas reales desde el punto de vista de su nihilidad. Veamos esto más detenidamente.

A diferencia de los relatos babilonios sobre la creación, y a diferencia también de la concepción expuesta en el Timeo de Platón, el relato del código sacerdotal, recogido en el primer capítulo del Génesis, evita sistemáticamente toda referencia a una materia primordial a parir de la que Dios habria modelado el mundo ${ }^{3}$. Sin embargo, hay que esperar al siglo primero a. C. para encontrar, en el segundo libro de los Macabeos, la tesis expresa de "que Dios hizo todo no desde los entes" (ouk ex ónton epolesen tó pánsa ho Theós, cfr. 2 Mc 7, 28). La misma expresión resuena en san Pablo, cuando éste nos dice que Dios llama lo que no es al ser (kaloûntos tò ónta hos ónta, Rom 4, 17). Tanto en el segundo libro de los Macabeos como en Pablo se trata de alirmar la esperanza en la resurrección apelando al poder creador de Dios. Pero no se trata de una fómula metafísica estricta, como tampoco lo es cuando Jenofonte dice que los padres generan a sus hijos ek mèn ouk ónion'. El segundo libro de los Macabeos no habla propiamente de una creación desde la nada (ex ouk ónton), sino que más bien se niega que Dios haya creado el mundo a partir de otras cosas anteriores (ouk ex b́nton). Pablo habla de un paso del no ser al ser, pero sin extender esto a toda la creación. De hecho, en la misma época en que se escribió el libro de los Macabeos, el autor del libro de la Sabiduría señalaba que Dios creó (ktisasa) el universo "a partir de la materia informe" (ex amófou hyles, cfr. Sab 11, 17).

Se discute si en Filón de Alejandría aparece la idea de una creación a partir de la materia informe, pero al menos lo cierto es que no argumenta en contras. Entre los primeros pensadores cristianos las fórmulas del segundo libro de los Macabeos y de Pablo comienzan a transformarse en una estricta descripción de la creación con las calegorías filosóficas helénicas. Asl nos dice el Pastor de Hermas que Dios hizo todo ek toû mé óntos eis to einai6: Dios hizo pasar las cosas del no-ser al ser. Sin embargo, la unanimidad no es total: en san Justino nos encontramos con la tesis de que Dios "fabricó" (demiourgêsai) todas las 
cosas "a partir de la materia informe" (ex amórfou hyles)". Justino utiliza la expresión del libro de la Sabiduria y no ve en ello ninguna contradicción con la posición de Platón, quien según Justino habría tomado de Moisés la cosmogonía del Timeo". También Alenśgoras parece haber sostenido ideas semejantes".

No obstante, lo cierto es que la teología cristiana pronto se inclinó a subrayar que la maleria informe también tiene que haber sido creada por Dios. Taciano subraya que la materia informe, antes de ser ordenada por el Verbo, fue creada por Dios ${ }^{10}$, y Teofilo de Antioquía critica expresamente la concepción platónica de una ordenación del mundo a partir de una materia informe, pues esto significaria hacer la materia pareja a Dios". El enfrentamiento con el dualismo de Marción y con la gnosis ha sido problablemente determinante para que a partir de Ireneo de Lyon la idea de una creación "desde la nada" (ex eo quod non erat, de nihilo) ${ }^{12}$ sea considerada unánimemente como parte del depósito revelado. El enfrentamiento de Agustín con los maniqueos será, naturalmente, una nueva ocasión de afurmar taxativamente esta creación de todas las cosas a partir de la nada ${ }^{13}$. Si el mundo ha sido hecho a partir de "alguna materia informe" ésta por su parte ha sido hecha de la nada ${ }^{14}$.

No cabe duda de que, en este sentido, tiene plena razón W. Pannenberg cuando señala que la teología cristiana logró con su idea de creación romper las limilaciones del concepto griego de la divinidad para abrirle espacio al Dios bíblico. En este sentido, la tesis de una "helenización del cristianismo", tal como la entendió la teología liberal protestante, ha de ser rechazada. Sin embargo, no es ésta precisamente la crítica de Zubiri. Para Zubiri el problema comienza por estar, como dijimos, en las consecuencias que esta idea ha tenido para la filosofía. Y es que la filosofia europea, a partir de san Agustín, encierra para Zubiri un "grave problema" nada menos que en su "estructura intema" (SPF II 116). Se trata de una filosoffa "que no ha nacido ni vivido desde sí misma", en inmediato contacto con las cosas, sino "con la mirada fija en el ente infinito" (SPF II 117). ¿A qué se debe esto?

\section{b) El Logos de Dios}

La razón es la siguiente. El relato del Génesis nos indica que Dios ha creado las cosas por el solo poder de su palabra (cfr. Gen l). Es la misma palabra de Dios que, a lo largo del Antiguo Testamento, acompaña la historia del pueblo de Israel y es uno de los conceptos claves - por mucho que no sea el único- para describir el acontecimiento de la revelación ${ }^{15}$. El prólogo del cuarto evangelio, además, identifica a Cristo con la Palabra misma de Dios. Cristo sería el Lógos divino hecho carne, que ha acampado entre nosotros. Se ha discutido hasta qué punto es la intención de este prólogo identificar la Palabra divina con el Lógos de la especulación helénica, siguiendo el camino iniciado ya por Filon de Alejandría. En cualquier caso, lo cierto es que la primera teología cristiana no 
dudó en identificar la Palabra creadora, salvadora y reveladora de Dios con el logos de los griegos.

Como es sabido, Zubiri entiende que el horizonte de la filosofía griega es el horizonte de la movilidad (cfr. SPF II 83-90; CLF ii-iii). El hombre se encuentra entre las cosas, pero no como una cosa más, pues está dotado de lógos. Este logos es justamente el que le posibilita ver, más allá del movimiento, lo que las cosas son, lo que siempre es, lo que permanece. Para el griego, cada cosa tienen en su haber, en su ousla, la configuración de lo que siempre es, "y con ella su fysis, su propia naturaleza, el principio mismo de su movimiento" (SPF II 88). El logos es justamente el órgano que permite acceder a lo que las cosas siempre son, es el órgano del ser. La verdad es entonces la patencia de aquello que las cosas son, expresado en un logos que sea conforme a ellas. La estructura del logos es entonces la que nos revela la estruclura íntima de lo real. Nada extraño entonces que los griegos confirieran a la realidad la estructura subjetual propia del logos predicativo (cfr. SE 75-94).

Para Zubiri, la identificación entre la palabra hebrea y el lógos griego es obra $\rightarrow$ todo lo preparada que se quiera por el judaísmo alejandrino- de la teología cristiana de los primeros siglos, y liene su máxima expresión en Agustín (cfr. SPF II 104-107). Filón de Alejandría ya había puesto en conexión la doctrina platónica de las ideas con el Logos divino. Para Orígenes, todas las ideas de las cosas están precontenidas en la Sabiduría divina ${ }^{16}$. Y Máximo Confesor señala también que los lógoi de las criaturas forman parte del Logos de Dios" ${ }^{17}$. De este modo, fue posible que Agusún pensara al Hijo etemo como la Palabra creadora, mediante la cual todas las cosas le son presentes a Dios incluso antes de haber sido creadas ${ }^{18}$.

En su enfrentamiento con las escuelas filosóficas de su tiempo, Agustín habría radicalizado la pregunta griega por la verdad, mostrando que en último término el escepticismo es "el resultado inexorable" del intento equivocado "de ver al hombre, al logos, desde la naturaleza" (SPF II 104). Ésta es la función histórica del escepticismo: haber mostrado que la verdad sobre las cosas se funda en una verdad más radical, la verdad sobre uno mismo. Y es que la verdad, para el cristianismo, es liberación (cfr. SPF II 107). Y esıa liberación se obtendria entrando en uno mismo para encontrarse allí con la huella de la verdad divina. Por eso, la verdad radical es en úlumo término, la verdad de Dios. En Dios es donde residiría la razón última de todas las cosas creadas:

san Agustín encuentra, tras largos años de inquietud intelectual, la realidad de la verdad en la realidad divina del logos de san Juan; en este momento la 'palabra de Dios' se ha convertido en 'razón del universo' y el mundo clásico se ha alojado definitivamente en el pensamiento cristiano (SPF II 109; cfr. DHC 137-138). 
De este modo, el hombre, creado a imagen y semejanza de Dios, tendría ciertamente

el lógos, la razón que Grecia le atribuia; pero la posee como participación en la razón universal, que, a diferencia de lo que pensaba el griego, se halla ahora en el espiritu divino (NHD 274).

Esto significa entonces que, en el nuevo horizonte filosófico, saber lo que es cada cosa "es sencillamente saberla en tanto que hecha por Dios, fundada en él. Es saberla desde Dios, verla en Dios, contemplarla" (SPF II 112). Esto implica, naturalmente, una nueva imagen del mundo creado:

habiendo interpretado san Agustín a Dios como logos o razón del universo, la creación es necesariamente una emergencia de una razón, con todos los caracteres que poseía el logos griego. La notura naturata, la naturaleza es así racional. Envuelve, pues, la creación dos dimensiones: de un lado, es una emergencia real de las cosas desde Dios; de otro, una manifesiación de una razón universal (SPF II 113).

Ciertamente, esta visión del universo va a experimentar una profunda evolución con la modernidad. Agusún ponía las ideas en Dios recurriendo al Hijo como Logos mediante el cual las cosas son creadas. La teología escolástica tratará de unir la presencia de estas ideas en Dios con la unidad de la esencia divina recurriendo a la idea de un conocimiento divino. Así, santo Tornás de Aquino sefialará que Dios se conoce a sí mismo como modelo de las criaturas ${ }^{19}$. El problema es que con ello se perderán los acentos uinitarios de la concepción agustiniana de la creación ${ }^{20}$. Pero, además, la concepción de una presencia de las ideas de las criaturas en la mente divina tenía el peligro de ligar a Dios a un determinado modelo de creación, con lo que se perdería la libertad del primero y la contingencia de la segunda. De ahí que Ockham se esfuerce por extraer las ideas de la mente de Dios. La realidad divina se convierte en pura libertad, y el logos vuelve a ser un alributo del hombre. Pero de un hombre segregado del universo. Asi interpreta Zubiri la situación de Descartes: el hombre está por primera vez solo, separado de Dios y separado de las cosas. Pero el hombre tiene ahora el logos no sólo por propiedad, sino por esencia, y con él va a iniciar la reconquista del universo y de la divinidad. Es el camino del idealismo hasta Hegel (cfr. NHD 273-284).

Pero el racionalismo, el subjetivismo y el idealismo no son, para Zubiri, las principales consecuencias tilosóficas de la teología cristiana. Se trata de algo más grave y más profundo, que Zubiri denomina justamente el "horizonte de la nihilidad". Y es que cada cosa real, contemplada desde el Dios que la ha creado y en quien está su razón de ser, "es como si no fuera, la cosa es una nada" (SPF II 112). De este modo, el hombre de la era cristiana ya no se pregunta por el ser como "acontecer actual del movimiento" (SPF II 112), sino por el ser en cuanto

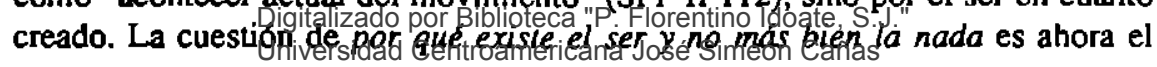


punto de partida de toda la filosofía europea desde Agusún hasta nuestro tiempo:

La filosofia, después de Grecia, filosofa desde la nada: para llegar a las cosas necesita de Dios, y el hombre mismo no es sino el camino del mundo hacia Dios (SPF II 114).

Es importante observar la radicalidad de la crítica de Zubiri a la filosolía moderna. El reproche que le dirige no es, como en el caso de Heidegger, el haber elaborado una "metafísica de la subjetividad". Para Zubiri, el subjetivismo no es más que un desarrollo interno al horizonte de la nihilidad. $Y$ es que en éste horizonte, al aparecer las cosas como una nada, el espíritu humano queda vuelto excéntricamente hacia la divinidad y segregado de las criaturas (cfr. NHD 274). Con la modernidad, el hombre se encontrará no sólo separado del mundo, sino también separado de Dios. Es justamente la situación de Descartes y de la filosofía modema. De ahí que Zubiri señale enérgicamenle la continuidad del mundo moderno con la teología cristiana (cfr. SPF II 115-116). No se trata de que los pensadores modernos sean teólogos cristianos, ni tampoco de que admilan explícitamente la idea de creación. Se trata de que, cristianos o no, piensan el ser de lo real desde la nada. Y en este sentido, la crítica zubiriana a la modemidad no sólo es más radical que la de Heidegger, sino que en cierto modo incluye al mismo Heidegger, por haber querido lograr el ser no desde los entes, sino desde la nada (cfr. SE 438-452).

\section{c) La persona como sujeto}

Decíamos que el "horizonte de la nihilidad", así entendido, empañó lo que Zubiri juzga como una de las aportaciones fundamentales del cristianismo a la historia del pensamiento filosófico: el concepto de persona. El problema es que tal concepto va a ser entendido fundamentalmente en têrmino subjetuales. En el pensamiento bíblico, los términos que podriamos traducir por persona no tienen, obviamente, carácter subjetual. La persona es ante todo una nefesh, esto es, un aliento vital, un soplo, un espíritu. Se trata de un concepto del que Grecia carecía (cfr. NHD). El origen del término latino persona está, probablemente, en el llamado análisis prosopográfico de la primitiva exégesis, y adquiere rango especulativo ya muy tempranamente, con Tertuliano. Su función decisiva en la teología es haber contribuido a dar la primera formulación rigurosa de la encarnación.

El Nuevo Testamento confiesa a Cristo como Hijo de Dios. Pero esto ha de ser expresado concretamente en el mundo griego y en la filosofía griega. Entonces la Iglesia afirma, ante todo, que la filiación divina de Cristo no consiste en una mera adopción (contra el adopcionismo). Cristo es verdadero Dios, y no la primera de las criaturas (Nicea contra Arrio). También lo es el Espíritu Santo (primer concilio de Constantinopla contra los pneumatómacos). Ahora bien, Cristo no puede consistir en una mera aparición de la divinidad bajo apariencia

Digitalizado por Biblioteca "P. Florentino Idoate, S.J."

Universidad Centroamericana José Simeón Cañas 
humana (contra el docetismo). Cristo es verdadero hombre. Dicho en términos griegos, en Cristo hay dos naturalezas, divina y humana. ¿En qué consiste entonces la unidad de la humanidad y de la divinidad? Tiene que ser una unidad física, y no meramente moral (contra Nestorio). Pero no puede ser una mezcla de naturalezas, ni la producción de una nueva naturaleza no humana ni divina. La unidad es física, pero personal. Cristo es una hypóstasis divina, es la segunda persona de la Trinidad (cfr. HR 268-277).

Ahora bien, la tendencia natural de la mentalidad griega es la de concebir esta hypóstasis como sustancia. Es algo que aparece incluso en la célebre definición de Boecio, según la cual la persona sería rationalis naturae individua substantia ${ }^{21}$. Ahora bien, el mismo Boecio comprende que esta definición no es aplicable a la Trinidad, y la evita en su tratado De Trinitate ${ }^{22}$. Y es que en la Trinidad solamente podría haber una sustancia, la divina, y no tres (triteísmo). En este sentido, hay que relativizar

el esfuerzo titánico de los capadocios para despojar al término hipóstasis de su carácter de puro hypokeimenon, de su carácter de subjectum y de sustancia, para acercarlo a lo que el sentido jurídico de los romanos había dado al término de persona, a diferencia de la pura res, de la cosa (HD 323).

Ciertamente, este esfuerzo titánico muestra que la helenización no consiste en una renuncia a lo más esencial del mensaje cristiano. Pero muestra también que nadie puede saltar por encima de su tiempo. Y es que, si bien la concepción de la persona como sustancia era incompatible con los contenidos trinitarios y cristológicos que se trataban de expresar, esto no impidió que la persona fuera pensada primariamente como sujeto. San Agustín, reacio al término hypóstasis, por sugerir -como reprochaban los arrianos a la posición ortodoxa- algún tipo de triplicidad en Dios, hablará de la persona en un sentido no sustancial. $Y$ es que, además de las tres facultades naturales del hombre, hay tras ellas un ego que las ejecula:

por medio de las tres yo recuerdo, yo pienso, yo deseo, yo que no soy ni memoria, ni inteligencia, ni voluntad, sino que las tengo. Por ello estas tres se predican de una persona que las tiene, pero que no es ninguna de ellas. En aquella suprema simplicidad que es Dios, aunque es un solo Dios, son tres las personas: Padre, Hijo, y Espíritu Santo ${ }^{23}$.

Para Agustín, en Dios no habría más que una sustancia, y las obras ad extra de las tres personas serían comunes. La persona no es aquí una sustancia natural, pero sí es un sujeto de sus actos, anterior y distinto de los mismos. Esta idea será decisiva, según Zubiri, para el desarrollo histórico del concepto de persona en la historia de la filosofía, concebida cada vez más según el molde de un sujeto ajeno a su naturaleza (Cfr. SH 106-107). En realidad, el concepto de sustancia y el de sujeto coinciden en referirse a un hypokeimenon subyacente a sus acciones y propiedades. Pero mientras que la idea de sustancia subraya el carácter natural

Digitalizado por Biblioteca "P. Florentino Idoate, S.J."

Universidad Centroamericana José Simeón Cañas 
de la misma, el concepto de sujeto señala justamente aquella segregación de la naturaleza que Zubiri ha señalado como característica del horizonte de la nihilidad. Sin embargo, el problema planteado por la teología a la filosofía moderna no se agota en la misma teología, sino que hunde sus raíces en un concepto griego entendido por ella en una perspectiva nueva: es el concepto de la realidad como algo subjetual.

Se puede decir que la concepción de la persona como sustancia y como sujeto ha marcado hondamente la historia de la teología. Ciertamente, no faltan voces discrepantes, como la de Ricardo de San Víctor, que sin duda creó una terminología original para hablar de las personas divinas. Estas estarian caracterizadas por su relación de origen (ex) respecto a la naluraleza divina, que sería una "sistencia". De ahí la introducción del vocablo "existencia". Si bien todo esto supone una idea radicalmente distinta de persona a la que el mismo Zubiri apelaba en los años cuarenta (NHD $477-478,483,492$ ), el planteamiento ricardiano no deja de estar cargado de muchos problemas comunes a la teología clásica. La naturaleza divina sigue siendo un substrato común desde el que se definen las personas, y no al revés. Por eso, el mismo Ricardo y su posterioridad siguieron hablando de Dios como sustancia. Las personas divinas tienden a convertirse en pura relación (ens minimum decía Tomás ${ }^{24}$ ), evilando así toda diferencia sustancial entre ellas. En Dios todo deberá ser considerado corno uno, mientras no haya obviedad de una oposición de relaciones. Además, las obras de la Trinidad ad extra, por estar realizadas por la sustancia común a las personas, tienden a ser consideradas al margen de su carácter trinitario, y la Trinidad se convierte cada vez más en un misterio más lógico y metafísico que estrictamente teológico y soteriológico. Es la escisión entre la trinidad económica y la inmanente, denunciada por Rahners.

La teología modema de la Trinidad ha tratado de salir al paso de estas dificultades de la concepción clásica. Pero, para hacerlo, no ha renunciado a la concepción de la persona como sujeto sino que, más bien, la ha radicalizado. La realidad divina deja de pensarse como sustancia o como naturaleza para pensarse primariamente como Sujeto. Aquí, las especulaciones trinitarias de la filosofía de Lessing y de Hegel han llevado en buena medida la delantera a la teología. Teólogos como Barth y Rahner han pensado desde esta perspectiva el tema de la Trinidad. La Trinidad no es otra cosa que la estructura de la aulorrevelación (en el caso de Barth ${ }^{26}$ ) o de la autodonación (en el caso de Rahner) de Dios a los hombres. En este sentido, Rahner señalará que las hipóstasis divinas no son personas en sentido estricto, por carecer de los atributos propios de un sujeto. Más bien habría que decir que la aulodonación de Dios tiene carácter trinitario, lo que nos revela tres modos distintos de subsistencia. Estos no serían meros modos de manifestación de Dios, pues la identidad entre la Trinidad económica y la inmanente asegura que tales modos caracterizan la propia esencia divina y por tanto sin ellos no habría divinidad ${ }^{27}$. 
Aunque esta concepción modema mejora en muchos aspectos el planteamiento clásico, no todos los problemas quedan resueltos. La revelación concreta de las tres personas divinas está subordinada a una concepción especulativa sobre la estructura trinitaria de esta revelación ${ }^{2}$. La realidad revelada de cada una de las tres personas y su respectividad interpersonal, tanto económica cono inmanente, queda en cierto modo opacada por su reducción a meros modos de subsistencia. Las relaciones de Jesús con su Padre tienden entonces a entenderse como un asunto propio de la humanidad de Jesús. Esto significa, en la cristología, un subrayado del inconfuse que pone límites a toda comunicación idiomática. Lo cual tiene entonces también consecuencias para la soteriologia: la entrega de Cristo en la cruz, aunque pertenece a la autodefinición de Dios, ya no pertenece a su autodonación estrictamente dicha ${ }^{29}$. Esto afecta en último término al concepto de Dios: la tesis neotestamentaria de que Dios es amor ha de ser reinterpretada en el sentido de que el Sujeto divino ejerce una actividad llamada amor. Pero, en cuanto sujeto, continúa siendo algo que está más allá de sus actos y ha de ser cuidadosamente distinguido de ellos ${ }^{30}$.

Teólogos contemporáneos como Moltmann y Pannenberg han tratado de salir al paso de estas dificultades, subrayando el carácter personal de las hipostasis y la ulterioridad de la esencia divina respecto a las procesiones personales. Zubiri mismo podria ser situado en esta perspectiva, como veremos (cfr. DHC 103). Ahora bien, tanto Moltmann como Pannenberg siguen tratando de resolver el problema en términos de subjetividad. Moltmann subraya el carácter estrictamente subjetual de las tres personas divinas. Éstas no consistirlan en unas puras relaciones ulteriores de una sustancia como quiere la teología clásica, sino que las relaciones serían en cierto modo ulteriores a su carácter subjetual. El problema entonces es cómo pensar la unidad de la Trinidad, que no podrla ser ni la de una sustancia ni la de un sujeto. Para Moltmann se trata de una pura unanimidad o concordia (Einigkeit) entre tres sujetos que serian anteriores a sus relaciones ${ }^{31}$. El rechazo de Molumann de la metafísica le lleva entonces a tener que cargar, aunque sea en un nuevo contexto, con las dificultades de los conceptos clásicos.

Pannenberg ha hecho un enorme esfuerzo en separar la idea de persona del concepto de sustancia, subrayando que el carácter personal es algo cobrado en los procesos de formación de la identidad. Sin embargo, sigue pensando que, más allá de los actos personales, hay que presuponer la realidad de un sujeto que los ejecula ${ }^{32}$. Ahora bien, este sujeto no es siempre un sujeto-de actos, sino primariamente un sujeto-a los procesos que lo configuran en un determinado campo dinámico. Esto significa en el fondo admilir algún tipo de distinción entre el dinamismo del campo, y los sujetos del mismo. En el caso de la Trinidad, este campo dinámico es el propio del amor entre el Padre y el Hijo. El campo aparece entonces como algo distinto de la realidad subjetual de las personas divinas. El problema se soluciona entonces atribuyendo al campo mismo un carácter personal: sería justamente la realidad del Espíriu Santo ${ }^{33}$. Pero entonces

Digitalizado por Biblioteca "P. Florentino Idoate, S.J."

Universidad Centroamericana José Simeón Cañas 
no es tan fácil pensar el carácter personal del Espíritu Santo, pues éste no es ningún sujeto-al campo, sino el campo mismo. La consecuencia es negar que el Espíritu Santo sea persona en sentido estricto ${ }^{34}$. En el fondo, la idea misma de sujeto es lo que también le ha impuesto a Pannenberg la necesidad de distinguir entre el amor y las personas, por mucho que la apelación al Espíritu permita una solución de compromiso. El sujeto (tanto el sujeto-de como el sujeto-a) siempre es alguien distinto de su actividad.

La creación desde la nada, la Palabra como Logos, la persona como sujeto: éstos son los graves problemas que Zubiri detecta en la historia de la teología europea. No sólo como problemas teológicos, sino como problemas que han condicionado el devenir mismo de la filosofía posthelénica. Por ello, la crítica de Zubiri a la función histórica de la teología es mucho más radical que las superficiales escaramuzas entre apologetas y anticlericales, tan características del panorama intelectual de nuestros días. Tampoco se trata de una mera protesta de la filosofía por haber sido considerada como ancilla theologiae. El problema, para Zubiri está en que esa ancilla estaba ya cargada de presupuestos teológicos en su misma estrucura interna, y no simplemente en su uso en función de la teología. Y por eso mismo, hacer "una filosofía pura que no sea más que pura filosofía" (SPF II 117), no es una simple sacudida de un yugo externo impuesto a la filosofía, sino más bien una ingente tarea de radicalización filosófica. Se trata de hacer una filosofía que nazca "de sí misma, frente a las cosas, en íntimo contacto con ellas" (SPF II 117). Como es sabido, Zubiri encontró justamente en la fenomenología el rumbo para esa vuelta a las cosas mismas, aunque su propio periplo intelectual le llevó mucho más allá de la fenomenología en el sentido habiual del término (cfr. NHD 9-17).

\section{La alternativa de Zubiri}

No es este el marco para exponer la filosolía de Zubiri. Pero sí es importante subrayar que el intento de elaborar una filosofía que "nazca de sí misma" le ha llevado a Zubiri a radicalizar la pregunta misma de los griegos. Zubiri no solamente se ha retrotraído hasta Parménides y Heráclito, como hizo Heidegger, para desde ellos replantear la pregunta auténtica de la filosofía que sería entonces la pregunta por el ser. Zubiri ha apelado, antes que éstos, al mismo Anaximandro. Solamente en su arkhé apuntaría la pregunta por algo que está "más allá del ser" (cfr. NHD 286-287; IRE 200). Esto que está más allá del ser no es - como a veces se ha dicho- Dios, sino justamente la realidad, el "de suyo". Y esta realidad no es inteligida primariamente por el logos, sino en lo que él denomina la "aprehensión primordial". Más radical que el logos de los entes, más radical que toda comprensión del ser, está la "impresión de realidad". Ésta es el punto de partida radical de las reflexiones de Zubiri. No lo es el sujeto que aprehende ni la sustancia aprehendida, sino el acto mismo de aprehensión (cfr. IRE 19-26). Y en este acto de aprehensión ni las cosas tienen carácter sustancial, sino

Digitalizado por Biblioteca "P. Florentino Idoate, S.J."

Universidad Centroamericana José Simeón Cañas 
sustantivo, ni el aprehensor es un sujeto tras sus actos, sino simplemente una realidad que se aprehende a sí misma como realidad, y por eso es reduplicativamente suya, es "suidad". Realidad frente a ser, aprehensión frente a logos, suidad frente a sujeto, serán tres de los conceptos claves que Zubiri utilizará en su enfrentamiento crítico con la historia entera de la filosofía, desde Parménides hasta nuestros días. Y aquí es donde está el núcleo de su posible relevancia para la teología.

La crítica a los conceptos tradicionales de ser, de logos y de sujeto en nombre de la realidad es muy importante para la teologla. No primariamente porque los conceptos de realidad, de aprehensión y de suidad puedan desempeffar un papel importante en la teología, sino ante todo porque muestra que el horizonte de la nihilidad no es un producto exclusivo de la idea cristiana de creación. Para que surgiera cl horizonce de la nihilidad fue necesario que la creación fuera pensada con las categorías helénicas. Paradójicamente, la radicalidad de La crítica filosófica de Zubiri respecto al papel hisúrico de la teología cristiana es justamente lo que le otorga una oportunidad a dicha teologia para mostrar que ella "no es formalmente solidaria de ninguna metafísica determinada. La metafísica griega no pasa de ser un modo, entre otros posibles, de entender la revelación" (DHC 12). En este sentido, el horizonte de la nihilidad sería, si se quiere, un horizonte cristiano, pero no un horizonte exclusivamente cristiano. Es algo fundamental para el grave y actual problema de la llamada "inculnuración" del crislianismo tanto en pueblos no europeos como en una Europa postmoderna. Todo ello no significa, en el caso de Zubiri, una apelación fundamentalista a una teología sin metafísica. Para Zubiri, ni siquiera la teología biblica es posible sin melafísica porque, en definitiva, la misma mentalidad semítica

y los conceptos en que estŕ plasmada constituyen, todo lo elementalmente que se quiera, pero siempre real y verdaderamente, una melofísica, que es el cañamazo del pensamiento bíblico (DHC 13).

Por ello, la teología no puede ni debe prescindir de la metafísica. Sin embargo, esta metafísica no tiene por qué ser ninguna de las formuladas en el horizonte europeo de la nihilidad, como es el caso de la metafísica propia de la mentalidad semítica. De ahi que el mensaje cristiano sea perfectamente compatible con otros horizontes intelectuales, tanto pasados como presentes. Y ésla es una de las intenciones principales, probablemente la principal, de las reflexiones teológicas de Zubiri. Veámoslo más detenidamente.

\section{a) Palabra y logos}

En el fondo de los problemas planteados por los conceptos de creación y de persona nos hemos encontrado con el problema del logos indoeuropeo. Para Zubiri, la logificación de la intelección lleva pareja una correlativa entificación de la realidad. Por eso, el griego piensa todo devenir como una dialéctica entre

Digitalizado por Biblioteca "P. Florentino Idoate, S.J."

Universidad Centroamericana José Simeón Cañas 
el ser y el no ser. La creación fue pensada como un gigantesco salto del no-ser al ser. Igualmente, la concepción de la persona como una sustancia o un sujeto anterior y distinto a sus actos es el resultado de la proyección de la estructura del logos predicativo sobre la realidad. El código sacerdotal nos presenta a Dios creando por el poder de su Palabra, y el prólogo del evangelio de Juan identifica esta Palabra (Lógos) con la manifestación del Hijo de Dios. En esta perspectiva, Dios aparece como la razón de las cosas, y el acto creador como un ejercicio de su logos divino concediendo el ser a unas criaturas idealmente precontenidas en su mente ( $C f r$. DHC 137). Ahora bien, hay que ver si la realidad de Dios (o de su segunda persona) y el carácler de su acción respecto al mundo están suficientemente caracterizados con el término "logos".

La respuesta de Zubiri, obviamente, va a ser negativa. Y para justificarla Zubiri va a seffalar, en primer lugar, que la identificación del dabar hebreo con el logos de la especulación helénica no es más que una posible opción entre otras. Siguiendo a von Soden, Zubiri subraya la enorme diferencia entre el concepto helénico y el hebreo de lo que es el verbo, el logos o palabra. Para el israelita la palabra comienza siendo algo que el prójimo me da, y en lo que se puede o no fiar (cfr. SPF I 94-96). De este modo, la verdad es ante todo veracidad, fidelidad, promesa de fuluro. No es algo que se ve, sino algo que acontece, y "por tanto. no es algo que se dice, sino algo que se hace, y pertenece, no a un presente, sino a un porvenir" (SPF II 95). Es la concepción joánica de un "hacer la verdad" (Jn $3,21)$. Y entonces la verdad no está oculta tras el movimiento, sino tras la historia. La verdad de Dios no es otra cosa que la fidelidad a su palabra en la historia. Y la fidelidad de Israel a Dios es la fidelidad a su palabra, expresada en la ley. Por eso, cuando el evangelio de Juan interpreta a Cristo como verdad y como palabra, "dijo en realidad, por lo pronto, que él era la nueva ley, el nuevo pacto o testamento entre Dios y los hombres, que su palabra es la palabra de Dios" (SPF II 100). No se trataba primariamente de identificar a Cristo con el lógos griego. sino con la fidelidad de Dios experimentada en la antigua alianza y revelada ahora en el Hijo (cfr. DHC 81).

Por esto, la realidad divina no ha de ser necesariamente entendida como logos. Desde un punto de vista meramente filosofico hay que señalar que Dios comienza siendo para la razón una realidad absolutamente absoluta, y no una realidad inteligente. El predicar la inteligencia a Dios no es, entonces, una traslación analógica de nuestra inteligencia humana a la inteligencia divina, sino la simple constatación que una realidad absolutamente absoluta ha de ser actual para sí misma. No se trata de proyectar antropomórficamente los caracteres de nuestra inteligencia sobre la realidad de Dios, sino más bien de concluir desde el carácter absoluto de Dios otros caracteres que ha de tener su realidad. Es lo que Zubiri denomina la "analogía del absoluto" (cfr. HD 169-171).

Ahora bien, el que la realidad divina sea inteligente no significa que esta 
inteligencia consista en logos. Aquí nos encontramos con una de las críticas fundamentales de Zubiri a la tradición filosofica occidental: ésta habría logificado la intelección, pensado que inteligir es formar conceptos, juicios y razonamientos. Sin embargo, Dios no tiene que formar conceptos, juicios y razonamientos para ser actual para sí mismo. En realidad, el logos no es otra cosa que una modalización ulterior de la inteligencia, y no su carácter formal. La intelección es para Zubiri la aprehensión de las cosas como reales. Si en el hombre hay un logos y una razón es justamente porque esta aprehensión primordial no alcanza a determinar lo que las cosas reales son en la realidad. Una inteligencia absoluta no necesitaría de logos. Es más, el logos supone siempre una dualización (cfr. IL 55-62), algo difícilmente predicable de una realidad absolutamente concreta y simple como la realidad divina.

Independientemente de cuáles fueran las intenciones del autor del cuarto evangelio, lo cierto es que la metafísica contenida en los conceptos que la revelación utiliza, tanto griegos como - aunque sea elementalmente - semíticos, no pertenece formalmente a la revelación (cfr. DHC 13). La primera teología cristiana habría apelado a esta concepción de Cristo como Verbo, pero esto no pasarían de ser unas consideraciones metafísicas no vinculantes (cfr. DHC 83, 208). En concreto, Zubiri rechaza las especulaciones llamadas "psicologicas" sobre la Trinidad (cfr. DHC 176), que serían uno de los sustentos, sobre todo en la teología latina desde Agustín, de la idea del Hijo como Verbo. Zubiri tendrá entonces que mostrar que hay alguna alternativa posible a la concepción de la segunda persona de la Trinidad como Logos o Verbo. Esto es justamente lo que Zubiri intenta en su toología trinitaria, al entender a Cristo como Verdad Real del Padre. Como veremos, la idea de persona como suidad no añade ninguna propiedad a la realidad divina, sino que solamente la determina como autoposesión tripersonal. Pues bien, la suidad del Hijo no consiste en otra cosa que en la actualidad de la realidad del Padre. La realidad absolutamente absoluta es principio y fuente de sí misma, y en esto consiste la persona del Padre. En cuanto que esta realidad absolutamente absoluta, por serlo, es actual a sí misma, puede decirse que tiene una verdad real. Y en esto consistiría la persona del Hijo: en ser la Verdad Real del Padre. La ratificación de la identidad de la realidad del Padre con la verdad real del Hijo sería justamente el espiritu de la verdad, el Espíritu Santo (cfr. DHC 101-107). Y para esto no se necesita ningún Logos:

lo propio de la inteligencia es justamente que en ella aquello que es inteligido cobra ... una actualidad. Nada más... Aquí no necesitamos para nada un verbum mentis. Nos basta con saber que ante la inteligencia aquello que está inteligido no por eso adquiere ninguna propiedad distinta de aquello que es, sino que pura y simplemente está actualizado. Y esta actualización es justamente lo que confiere a la realidad inteligida su carácter de verdad. Verdad es primariamente la actualidad de lo real en la inteligencia... $Y$ es justamente por esto la verdad real (DHC 102).

Digitalizado por Biblioteca "P. Florentino Idoate, S.J."

Universidad Centroamericana José Simeón Cañas 
El Padre da de sí una segunda suidad, distinta de la propia. Y esta segunda suidad es una suidad de verdad. No es una procesión desde la esencia del Padre, como pensaría la teologla griega, sino una procesión de persona a persona Teniendo la misma realidad, serían dos suidades distinlas. Se podrá decir que esto es un postulado especulativo. Sin duda lo es. Lo único que Zubiri pretende es que ella constiluye una mejor exposición de los datos revelados que la tesis, también especulativa, según la cual el Hijo es un verbum mentis consustancial al Padre (cfr. DHC 103-104).

También se podría pensar que el hablar del Hijo como un Logos, si bien no es apto para describir su realidad misma, sí puede ser adecuado para hablar de las obras urinitarias ad exura. La creación es una creación en Cristo (cfr. 1 Co 8, 6; Col 1, 13-20; Hb 1, 1-8; Jn 1, 1-8), y ello implicaría que aquella palabra creadora de la que nos habla el Génesis podría ser interpretada, como hizo la teología clásica, desde el Logos del Hijo. La distinción entre un Logos inmanente y un Logos proferido es la distinción entre la funcionalidad económica de la Trinidad y su transcendencia ( $c f r$. DHC 83, 134), pero no anula el que en ambos casos el Logos en cuestión fuera interpretado por los primeros teólogos cristianos como el Logos del Hijo. Sin embargo, el problema está en que esta idea del Logos creador supone una concepción de la creación como paso de la nada al ser: el logos de Dios conferirla el ser a las cosas diciendo que éstas "sean" ( $c f r$. DHC 133-134). Más adelante veremos que la tesis de una creación "de la nada" no implica una melafísica del ser. Incluso el verbo empleado por el Génesis no es necesariamente el verbo ser, sino un verbo más cercano al estar o al haber (cfr. DHC 134). En cualquier caso, la concepción hebrea de que Dios crea por el poder de su palabra no aboca necesariamente a una identidad de esta palabra con el logos helénico. En primer lugar, la idea de una creación por la palabra no es una concepción exclusiva de Israel, como se ha dicho con tanta frecuencia, sino que se encuentra también en las mitologías de otros pueblos ${ }^{35}$. Y, en segundo lugar, la creación por la palabra, como la creación desde la nada, no es más que una forma vulgar de expresar la independencia de la iniciativa divina respecto a cualquier "material" usado para la creación, y no el carácter formal del acto creador. El carácter trinitario del acto creador no implica tampoco la necesidad de hablar de Dios como un logos. El acto creador no es un segundo acto respecto a lo que es Dios como actividad pura (cfr. DHC 147). Se trata de la efusión de la propia vida divina, una "procesión de las criaturas ad extra del Padre por el Hijo en el Espíritu Santo" (DHC 144).

Pero para conceptuar esto es suficiente, según Zubiri, con decir que el Hijo sea la Verdad Real del Padre, y no su Logos. La creación, vista desde una perspectiva trinitaria, no consiste en otorgarle la existencia a unas ideas contenidas en el Logos divino, sino en la procesión ad exira de la vida divina así entendida. La creación significa que, además de las procesiones trinitarias, hay una procesión de alteridad, una procesión transcendente (cfr. DHC 145). Y para ella no se

Digitalizado por Biblioteca "P. Florentino Idoate, S.J."

Universidad Centroamericana José Simeón Cañas 
necesita de ningún Logos, sino solamente de la proyección de esta vida divina fuerá de sí misma Con esto se resuelven dos graves problemas del planteamiento clásico ${ }^{36}$ : en Dios no hay ninguna de las dualidades propias del Logos, y Dios no está sometido a ningún modelo "racional" a la hora de crear el mundo.

Zubiri entiende que cuando el Nuevo Testamento habla del Hijo como Logos lo hace para referirse a su carácter revelador (cfr. DHC 81). Sin embargo, esto tampoco significa que la revelación tenga como estructura formal el logos. Cuando Zubiri insiste repetidamente en que la revelación no es un dictado ( $c f r$. HR 72, 82, 182, 210, 228, 282), no pretende solamente desprenderse de ciertas concepciones más o menos míticas de la misma, sino que quiere también librarse de una idea proposicional tanto del acto revelador como de sus contenidos. Hoy dia es muy frecuente sostener que, si bien el acto revelador no consiste formalmente en un dictado de proposiciones, los contenidos de la revelación y la trasmisión de la misma en la historia sí estarian integrados fundamentalmente por el $\operatorname{logos}^{37}$. Así, por ejemplo, se pretende con frecuencia que los misterios fundamentales del cristianismo líenen un carácter lingüístico. Ello es en el fondo la consecuencia de una concepción de la comunicación, según la cual ésta consiste fundamentalmente en lenguaje. Si la revelación consiste en una comunicación de Dios a los hombres, lo obvio sería entonces pensar que lo decisivo de la encarnación es que Dios nos habla ${ }^{30}$, lo decisivo del reino es el anuncio del mismo ${ }^{39}$, y lo decisivo de la cruz es la "palabra de la cruz" anunciada en la predicación ${ }^{40}$. La palabra es la esencia de la historia ${ }^{41}$, y el acercamiento de Dios a la historia humana termina no siendo más que un acercamiento a la palabra y en la palabra.

La alternativa a estos reduccionismos no consiste solamente en ampliar el concepto de revelación a toda la historia de las cosmovisiones humanas en cuanto se preguntan por lo divino, al estilo de Pannenberg. Ciertamente, la "palabra" de la que nos habla la escritura no es mero logos, sino que remite a un contexto significativo más amplio ( $c f r$. DHC 48-49). En esto es acertada la crítica de Pannenberg a la teología luterana de la palabra. Pero el contexto más amplio al que hay que apelar no es simplemente la revelación. Toda la polémica de Pannenberg contra Jüngel y Ebeling en tomo a la palabra de Dios no sale del plano de una teología de la revelación. Ciertamente, tal teología es muy legítima mientras que el contenido del cristianismo no sea reducido a sus aspectos intelectivos. Pero para Pannenberg, estos aspectos inteleclivos son decisivos, por la sencilla razón de que la salvación cristiana se funda en la identidad que determinadas cosmovisiones pueden aportar en cuanto respuestas a la pregunta por la verdad de la totalidad. La revelación es, en este sentido, fundamento de la salvación y el cristianismo, más que una religión de salvación sería una respuesta verdadera a la verdad de la Lotalidad $^{42}$.

Como es sabido, dabar en hebreo no sólo significa palabra, sino también

Digitalizado por Biblioteca "P. Florentino Idoate, S.J."

Universidad Centroamericana José Simeón Cañas 
"hecho" o "acontecimiento". No deja de ser interesante que la filosofia conternporanea del lenguaje ha remitido el significado de las expresiones lingüísticas a su contexto práctico. En cualquier caso, para Zubiri el acontecimiento en el que se funda la palabra no es otro que lo que él llama "deiformación". Si no habla de deificación es simplemente porque ésta connota clásicamente la acción de la gracia sobre la vida de los justos, y no una dimensión teologal de todo hombre, incluso del condenado (cfr. DHC 19-20). La deiformación atafte a todo hombre por ser éste, desde el punto de vista del cristianismo, la proyección ad exira de la vida misma de Dios (cfr. DHC 23). Esta deifomación es para Zubiri el sentido fundamental del cristianismo. El cristianismo no es primariamente una revelación, sino una deiformación. La deiformación no consiste en una identidad que la revelación proporcionaría, sino que la revelación sería el aspecto intelectivo de la donación real de Dios al hombre. Y por eso toda teología de la revelación ha de fundarse en una teología de la deiformación. Para Zubiri no se puede

entender jamás la donación de Dios al hombre en función de la revelación, sino que -al revés- hay que entender la revelación de Dios desde la donación que él hace de sí mismo al hombre (DHC 366).

La deiformación es, también, algo más radical que la salvación. Para Zubiri, el cristianismo no sería primariamente una religión de salvación. Es decir, no consistiría primariamente en una respuesta a las indigencias y a los males de la vida humana, sino al revés. La deiformación que el crislianismo ofrece sería el fundamento de la salvación (cfr. DHC 4-5). La salvación no sería otra cosa que el dar a la deiformidad primaria que el hombre tienen como crialura la capacidad de inscribirse dentro del poder de Dios, librándose del poder del mal objetivado en el mundo ( $f f r$. DHC 286). Y es que, para Zubiri, el pecado original no consiste en ningún lipo de epidemia hereditaria, sino en un pecado de origen moral que ha adquirido poder en el mundo social e histórico de los hombres (cfr. DHC 277ss). Ahora bien, la inscripción del hombre bajo el poder de Dios es algo que se funda en su deiformación primaria y radical. La deiformación es, en este sentido, tanto el fundamento de la salvación corro el fundamento de la revelación. Y ello supone una concepción del cristianismo distinta de la habitual: éste no sería una religión de salvación, sino una religión de deiformación.

Por eso, cuando Zubiri afirma que la historia es la revelación en acto, es menester entender correctamente esta tesis. No se trata de identificar, como en el caso de Pannenberg, la historia humana con la historia de tradición, entendiendo por tal la transmisión de las distintas cosmovisiones humanas, para después preguntarse en cuál de ellas se responde más satisfactoriamente a la pregunta por lo divino. Porque aquello que Zubiri entiende por historia va mucho más allá de la mera tradición cosmovisional. La historia es entrega de formas de estar en la realidad, con todos sus momentos físicos, prácticos e intelectivos. La revelación atañe y envuelve al hombre entero, no sólo a su inteligencia. Y la inteligen-

Digitalizado por Biblioteca "P. Florentino Idoate, S.J."

Universidad Centroamericana José Simeón Cañas 
cia que la revelación envuelve no es primariamente su inteligencia concipiente, su logos, sino su inteligencia sentiente, su modesta y radical aprehensión de lo real en tanto que real ( $c f r$. DHC 369). Esto no excluye, claro está, que ulteriormente la revelación exige e incluya la rellexión misma (cfr. DHC 368).

Ahora bien, la revelación, en lo que liene de comunicación, no es primariamente la entrega de un logos, sino algo más modesto y más radical, que es la donación física de Dios a los hombres. Esta donación tiene un carácter manifestativo, y por ello acontece en la religación de todo hombre, pero tiene un carácter más especial y concreto cuando hay una entrega de fe. Esta entrega, posibilitada por Dios, es la que abre el ámbito en el que la manifestación es formalmente revelación ( $f f r$. DHC 366ss). Pues bien, la revclación, desde el punto de vista del cristianismo, culmina en Cristo, religación subsistente. La revelación divina, en este sentido, es algo que está inscrito "en la convivencia de Cristo con los hombres" (DHC 18). Y, en esta convivencia, la vida del otro

no es aprehendida como mero 'objeto', sino como algo 'convivido' por el aprehensor. Si no fuera asi, el conocimiento del otro no pasaría de ser una mera información o una ciencia extrínseca a lo conocido. El logos aprehensor sólo es posible por 'convivencia' (DHC 18)

$Y$ es que, en delinitiva, Cristo no lunda el cristianismo trasmitiendo un mensaje, una cosmovisión, unas normas y valores sino, más radicalmente, haciendo cristianos. Configurando por sus acciones el Yo de las personas que le rodeaban (cfr. DHC 291), y poniendo de este modo en marcha el dinamismo personal e histórico de la incorporación a su persona. En los escritos teológicos que poseemos, esta acción de Cristo es conceptuada por Zubiri lundamentalmente en términos de realidad y de ser. Para Zubiri, el ser es la actualidad ulterior de la realidad en el mundo. El Yo del hombre no es oura cosa que su ser, y lo que la obra de Cristo aportaría al hombre sería esta deiformación según el ser de Cristo. Probablemente, algunos conceptos que Zubiri perfila en años ulteriores, como es el concepto de actualidad o el de capacilación, podrian ser muy frucúfieros a la hora de conceptuar más detenidamente en qué consiste esta incorporación. En cualquier caso, lo decisivo es que la deiformación, con todos sus aspectos individuales, sociales e hislóricos, es un dinamismo personal puesto en marcha por Cristo. Y esto nos remite a otro concepto capital: el concepto de persona.

\section{b) La persona como suidad}

Con el concepto de persona Zubiri no busca primariamente, como hemos dicho, una nueva sistematización teológica de los problemas propios de la doctrina trinitaria o de la cristología, sino que pretende más bien mostrar cómo es posible la reflexión teológica fuera del horizonte de la nihilidad. Para Zubiri, la persona se caracteriza por ser formal suidad. El hombre es persona porque, en

Digitalizado por Biblioteca "P. Florentino Idoate, S.J."

Universidad Centroamericana José Simeón Cañas 
virtud de su inteligencia, aprehende su propia realidad como real. Por eso es formal y reduplicativamente "suyo", más suyo de lo que puede ser cualquier animal (cfr. IRE 211-212). La realidad divina, claro esட́, no es personal por ser inteligente, sino por ser una realidad absolutamente absoluta que, como tal, se posee absolutamente a sf misma (cfr. HD 168). En cualquier caso, ni la persona humana ni la persona divina consisten formalmente ni en ser sustancias naturales ni en ser sujetos (DHC 89, 93, 213, 231). La idea de la persona como sujeto o como sustancia es, en realidad, el resultado de la proyección del logos indoeuropeo sobre la estructura de la realidad. Según Zubiri, es la suidad como autoposesión lo que formalmente caracteriza a la realidad personal. Y esto supone que la persona no es alguien anterior a su accividad, sino que la realidad personal es una realidad formalmente dinámica en y por sí misma: es el dinamismo de la suidad (cfr. EDR 205-245). Y esto tiene consecuencias muy decisivas para la teologia.

Piénsese solamente en la cristología. La persona de Cristo no puede ser pensada como un sujeto anterior a sus actos (cfr. DHC 252). El ser persona y el saberse como persona es algo que acontece justamente en las acciones humanas en la medida en que éstas actualizan la propia realidad (cfr. DHC 237). Eswo es algo que le permite a Zubiri dar una respuesta original al problema del saber que Cristo tuvo sobre su propia realidad, pues evita todo planteamiento del mismo en términos de conciencia. Pero tiene además otras consecuencias no menos graves. Si ser persona no consiste en ser un sujeto anterior a la propia actividad, sino más bien la autoposesión que en esta actividad transcurre, esto significa que la aclividad misma de Cristo no es ajena a su persona. Los misterios de la vida de Cristo cobran entonces una relevancia cristológica de primera magnitud, pues en ellos es donde transcurte la autoposesión en que la segunda persona de la Trinidad consiste. Esto enlaza, naturalmente, con el interés de muchas cristologías latinoamericanas de fundamentar la cristología en la praxis de Jesús ${ }^{43}$. No se trata, desde la perspectiva de Zubiri, de un mero moralismo de cualquier clase, sino de integrar la actividad de Jesús en la definición misma de su persona.

Esto tiene también importantes consecuencias para la teología trinitaria. Zubiri puede decir, con Rahner, que las personas divinas no pueden ser consideradas como sujetos (cfr. DHC 73). Pero campoco son, en sentido estricto, subsistencias. Este concepto, además de sus connotaciones sustancialistas (que Agustín mismo observó), sería en todo caso algo ulterior a la suidad (cfr. SH 115-117; DHC 230, 96). Pero carecer de subjetualidad y de subsistencia no significa carecer de carácler personal. Las personas divinas son personas por ser suidades, y no por ser sujetos de actos. Y esto es algo que se puede y se debe decir en sentido estricto de las tres personas, también del Espíritu Santo, por mucho que en la revelación no aparezca como un yo ni como sujeto. El Espíritu Santo, desde la perspectiva de Zubiri, sería persona en sentido estricto, por mucho que no fuera ni un yo ni un sujeto.

Digitalizado por Biblioteca "P. Florentino Idoate, S.J."

Universidad Centroamericana José Simeón Cañas 
Las personas así concebidas son el punto de partida para conceptuar la realidad divina. Zubiri no parte de la esencia para conceptuar la suidad sino que, a diferencia tanto de la teología latina (que parte de la esencia común a las personas) como de la teología griega (que parte de la esencia en cuanto poseída por el Padre), considera que es la suidad el punto de partida para conceptuar la esencia. De las misiones trinitarias se pasa a las procesiones, y de las procesiones se pasa a la pregunta por la realidad misma de Dios. Es el itinerario que Zubiri describe con los conceptos de funcionalidad, transcendencia, y consubstancialidad o divinidad (cfr. DHC 92). Este no es sólo el camino histórico que la Iglesia recorrió para llegar a hablar de Dios como trino, sino que es también el orden que se ha de seguir en la consideración "especulativa" del misterio (cfr. DHC 95-96).

$Y$ es que el concepto de persona que Zubiri ha elaborado no añade nada a la realidad y "por eso puede identificarse con ella sin hacerla "compuesto"' (DHC 96). El partir de las suidades no exige, como sí exige la idea de sustancia, negarle el ser de las personas para convertirlas en puras relaciones. Tampoco exige distinguir entre los sujetos y sus dinamismos. Las personas mismas no añaden nada a la realidad divina, sino que se idenifican con ella. Y esto significa entonces que la historia en la que estas personas se han revelado es el punto de partida para conceptuar su realidad. La originalidad de Zubiri no está, obviamente, en partir de la hisioria; esto es prácticamente un lugar común en la teología actual. Tampoco está en afirmar la identidad entre Trinidad económica y Trinidad inmanente, pues esto es algo que Zubiri, en virtud de su concepto de la revelación, tiene que aceptar ${ }^{\text {at }}$. Su originalidad está más bien en haber elaborado un concepto de persona que permite una conceptuación rigurosa del punto de partida económico.

El punto de partida determina también la conceptuación de la realidad divina en sí misma. Habiendo partido de las personas, estas no aparecen como "existencias" delinidas por su relación de origen respecto a su esencia común, sino que la esencia común es en cierto modo el resultado de las procesiones trinitarias (Cfr. DHC 103). La respectividad interpersonal es entonces lo que define la realidad divina, y no al revés. Para Zubiri, "la constitución de la propia esencia divina como un acto puro es - sit venia verbo- el precipitado de las procesiones personales en que la Trinidad en cuanto tal consisle" (DHC 144). No se parte de la esencia común ni de la esencia en cuanto poseída por el Padre, sino de las personas divinas y sus procesiones, y desde ellas se nos dice qué es la realidad divina. Como en la teologia griega, Zubiri parte de la persona del Padre, pero no en cuanto poseedora de la esencia divina, sino solamente en cuanto persona (cfr. DHC 100s), pues sólo desde las procesiones personales se puede decir qué es la realidad divina. Esta consiste entonces en un dinamismo procesual. 
Ahora bien, las procesiones no son operaciones ejecutadas por una sustancia o por un sujeto (cfr. DHC 97-98). Toda realidad es por sí misma formalmente dinámica. Y este dinamismo consiste en lo que Zubiri denomina un "dar de sr", anterior a todo cambio. El dinamismo no es entonces, como pensaron los griegos, una combinación entre ser y no-ser. En realidad, la idea del devenir como una combinación de ser y no-ser obedece a la proyección de la estructura del logos predicativo indoeuropeo sobre la estructura de la realidad. La misma idea aristotélica de potencialidad no sería otra cosa que un modo de introducir el no-ser en la estructura de la realidad. Para Zubiri, loda realidad, con anterioridad al ser y al logos, es constitutivamente dinámica (cfr. EDR 12-67). También lo es la realidad divina, a diferencia de lo que pensaron los griegos. La realidad absolutamente absoluta de Dios es una realidad absolutamente dinámica (cfr. HD 168). Dios es un absoluto dar de sí. Los primeros apologistas ya identificaron la inmulabilidad e inmortalidad divinas con la ausencia de todo dinamismo en Dios, justamente porque pensaron que el dinamismo exigiria atribuirle a Dios algún tipo de no-ser, y por tanto de imperfección $n^{45}$. En cambio, Zubiri entiende que el dinamismo es algo anterior y más radical que el cambio. De este modo, es posible concebir la realidad divina como un absoluto dar de si como actividad pura (cfr. NHD 479; DHC 97-99), sin introducir en él ningún tipo de no-ser.

Por la revelación sabernos que este dar de sí es formalmente un dar de sf urinitario. La actividad que formalmente caracteriza a la realidad divina es un dar de sl de unas personas a otras en las procesiones. Por eso no es posible distinguir entre la realidad divina y las procesiones, sino que su esencia misma es procesión. La vida divina no consiste en ser naturaleza (cfr. DHC 213, 231; HD 162,309, 312), sino en "la unidad y la simplicidad insondables de una actividad real y efectiva" (DHC 99), que no es otra que la del amor. El amor no es una aclividad que un sujeto o una sustancia divina ejecutan en relación al mundo. Tampoco es una actividad ulterior a la constitución de los tres sujetos divinos, como diría Moltmann". La realidad misma de Dios, que no es otra que la de las personas, es la que formalmente consiste en amor, según la escritura (cfr. $1 \mathrm{Jn} 4,8$ ). Es el amor en que consisten las procesiones divinas, cuyo precipitado es la realidad misma de Dios.

Sin embargo, el "dar de si" de la realidad divina no se agoba en las procesiones trinitarias. Además de éstas hay una procesión de alteridad, una procesión transcendente, que es justamente la creación. La creación, vista desde esta perspectiva, no es otra cosa que la versión ad extra (alteridad) de esta actividad insondable en la que Dios consiste. Veámoslo más detenidamente.

\section{c) Una creación sin nada}

Dadas las repercusiones filosoficas que ha tenido el concepto cristiano de creación, Zubiri ha de comenzar delimitando los campos de la teologia y de la

Digitalizado por Biblioteca "P. Florentino Idoate, S.J."

Universidad Centroamericana José Simeón Cañas 
filosofía. Para Zubiri, que apela a Escoto, la creación es una verdad de fe, no accesible a la razón con independencia de la revelación (cfr. HD 153; DHC 90) y por tanto no perteneciente en la estructura intema de ninguna filosofía. La mostración de la existencia de Dios no es ni puede ser una prueba de la creación $n^{47}$. Lo que la filosofía puede llegar a mostrar, a los ojos de Zubiri, es justamente la presencia fundante de Dios en todas las cosas reales, sobre la cual se montará ulteriormente toda explicación en términos de creación.

Y esta presencia consiste en que la realidad de cada cosa está constituida 'en' Dios. Dios no es una realidad que está ahí además de las cosas reales y oculta tras ellas, sino que está en las cosas reales mismas de un modo formal. Por tanto, la realidad absolutamente absoluta es ciertamente distinta de cada cosa real, pero está constitutivamente presente en ésta de un modo formal. Por esto es por lo que toda cosa real es intrinsecamente ambivalente. Cada cosa, por un lado, es concretamente su irreductible realidad; pero, por otro lado, está formalmente constituida en la realidad absolutamente absoluta, en Dios (HD 148-149).

Ello significa entonces que Dios no está segregado del mundo, y el acceso a él no consiste por tanto en una huida del mundo, sino en una profundización en la realidad de las cosas (cfr. HD 148, 174ss, 260, 308, 351, 378). Esto no es panteísmo porque Dios es una realidad absolutamente absoluta respecto al mundo. Pero tampoco se puede decir que el mundo y Dios sean "dos" realidades. Dios y el mundo no son dos, pero tampoco son uno. No se trata ni de identidad de dualidad, sino justamente de transcendencia (cfr. HR 145-146). Dios es transcendente "en" las cosas, sin estar separado de ellas: es lo que Zubiri expresa diciendo que "Dios transciende al mundo, pero el mundo es inmanente a Dios" (EFM 13). Esta tesis, que corresponde propianente a la obra sobre El hombre y Dios, es en última instancia consecuencia del camino elegido: Zubiri no parte del cosmos ni de la subjetividad humana para llegar a Dios, sino de la intima unidad entre realidad y aprehensor en el hecho de la religación (cfr. HD 126-127).

Ahora bien, lo esencial es entonces que se nos diga cómo, en esta perspectiva y en este nuevo horizonte, es posible conceptuar la creación una vez que nos encontramos con una revelación que nos la propone. Ciertamente, Zubiri acepta lo que con la fómula clásica de la creación ex nihilo sui et subjecti se quiere decir, pues entiende que esto refleja correctamente las intenciones del texto revelado. Dios crea algo nuevo que no habia antes y lo crea sin partir de ningún "material" previo. La creación tampoco es una emanación de la realidad divina, pues Dios pone en la creación algo otro, transcendente a su realidad. Y esto, según Zubiri,

es lo que se expresa vulgarmente diciendo que Dios hace las cosas desde la nada. Término o expresión completamente equivoca, porque la nada por ser

Digitalizado por Biblioteca "P. Florentino Idoate, S.J."

Universidad Centroamericana José Simeón Cañas 
nada no es ni tan siquiera un 'desde'. Lo que se quiere expresar es que no hay un sujeto anterior (DHC 122).

Por eso no es necesario interpretar la nada en términos de no-ser. Si la filosofla griega se hubiera mantenido tiel a la tesis de Parménides, según la cual no se puede otorgar ser al no-ser, nunca hubiera podido conceptuar el movimiento. La solución no está en concederle algún tipo de entidad al ser, como hicieron Democrito o Platón, sino en preguntarse si es correcta la idea del movimiento como una dialéctica de ser y no-ser. Para Zubiri, la realidad es en sí misma dinánica, con anterioridad a toda "dia-léctica". En realidad, la idea griega del movimiento procede, como dijimos, de una proyección de la estructura dialéctica del logos (valga la redundancia) sobre la estructura de lo real. Cuando el Pastor de Hermas entendió la creación como un paso del no-ser al ser no hizo otra cosa que asumir siglos de especulación helénica.

Por eso, cuando la teología ha querido explicar de algún modo esta procedencia "de la nada" se ha encontrado con los mismos problemas que los griegos, y se ha sentido tentada a olorgarle algún tipo de entidad para que pudiera ser un "desde" respecto al acto creador de Dios. Asi, por ejemplo, Karl Barth la ha identificado con la "negatividad", y ha pensado que esta negatividad consiste en la resistencia frente a Dios" ${ }^{4}$. Ahora bien, esto es imposible desde la perspectiva de Zubiri. En primer lugar, porque la conceptuación del mal como negatividad es una herencia de la metafísica griega harto cuestionable. Para Zubiri, el mal no es carencia de realidad o imperfección, sino que tiene realidad positiva. Ahora bien, esta realidad positiva del mal no es algo anterior a la creación, sino que es una condición - no importa ahora cuál- de la realidad creada (cfr. SSV 235-256). En segundo lugar, otorgarle algún tipo de realidad a la nada supone una recaída en las concepciones, si no míticas como quiere Pannenbergth, sí al menos dualistas, propias de la mentalidad griega. Y como vimos, estas concepciones no son compatibles con la idea bíblica de creación.

La nada no es para Zubiri más que una expresión vulgar con la que se señala simplemente que antes de la creación no hay ningún material previo, que Dios después modelaría. Pero esto no significa que la creación consista formalmente en un paso del no-ser al ser. Esto no es más que una ingente entificación de la realidad. Las cosas, en última instancia, no proceden de la nada, sino que proceden del acto creador del mismo Dios:

De ahí es de dónde proceden y no de la pura nada. La pura nada se invoca precisamente para expresar el carácter total y positivo del acto creador, a saber: que no se apoya en ninguna realidad (EFM 17).

¿Cómo se puede conceptuar entonces la creación? Aquí hay que comenzar por recordar que toda realidad, en la concepción de Zubiri, es dinámica en y por sí misma. De ahl la gran diferencia entre la posición de Zubiri e intentos como 
el de Juingel. Toda las críticas de este gran teólogo a la metafísica occidental no le han liberado de un prejuicio fundamental de esa tradición: la idea de que para introducir el dinamismo en Dios es necesario insertar de algún modo la negatividad en la realidad divina. Ciertamente, Jüngel subraya que tal inserción no se hace en función de consideraciones metafísicas, sino a partir de la revelación de Dios en el destino del crucificado. Sin embargo, aquí se sigue suponiendo que el mal y la muerte con los que Cristo carga en la cruz consisten formalmente en negatividad. Es algo que incluso asume el lenguaje usual. Sin embargo, ello no obsta para que la tesis esté cargada de metafísica griega, según la cual el mal consiste, como el movimiento, en una carencia de entidad (cfr. SSV 247-249). Para Zubiri, en cambio, la plenitud de realidad es plenitud de actividad, sin que ello implique ni cambio, ni negatividad, ni imperfección. El carácter dinámico de la realidad divina y su presencia formal en cl cuerpo muerto del crucificado (DHC 253) no implican la auribución de algún lipo de negatividad o de potencialidad a Dios $^{30}$.

Este dar de sí no es en Dios necesariamente creación. El modo primario del dar de sí es, según la concepción cristiana, justamente lo que la teología trinitaria ha llamado procesión. Sin embargo, Dios puede tener un dar de sí ad extra. $\mathrm{Y}$ este dar de sí ad extra es justamente la creación. Ahora bicn, el acto creador no es, como pensaría un griego, el primer movimiento de Dios, quien por tanto, necesitaría de la nada para poder ser movimiento. En realidad, la idea de una creación de la nada, interpretada en términos griegos, no hace justicia a la tolal independencia de Dios. El acto creador procede de Dios y nada más que de Dios, porque éste ya es en sí mismo dinámico. Y lo que hace Dios es justamente proyectar ad extra su vida divina. Este proyectar ad extra no es más que poner, en la realidad, la alteridad. La creación no es entonces otra cosa que la posición de la alteridad sin alteración del Creador (cfr. SSV 289; HD 175-176). Y es que para Zubiri Dios

es la realidad en el sentido más intrínseco y pleno del vocablo. Esto quiere decir que la transcendencia de su térnino, la alteridad que ha puesto, es la alteridad de lo real en tanto que real. Esto es lo que formalmente constituye la creación. Es justamente la posición de la alteridad de lo real en tanto que real, sin alteración ninguna de la realidad que lo pone (DHC 121).

La tesis de Zubiri podría recordar la concepción hegeliana según la cual el Hijo es en la Trinidad el principio de la alteridad y por tanto el punto de partida no sólo para la génesis de las realidades finitas frente a la realidad divina, sino también el principio de la multiplicidad, en cuanto alteridad respectiva, de unas cosas reales frente a otras". Sin embargo, para Hegel, se trata de una génesis necesaria a partir del desarrollo dialéctico de un Sujeto Absoluto ${ }^{32}$. Para Zubiri, en cambio, en Dios no cabe ningún desarollo dialéctico, pues en Dios no hay ningún logos, como vimos. Y por ello ni el dinamismo de la realidad divina ni 
la génesis de las realidades finitas necesitan que en la realidad divina haya ni ser ni no-ser. De este modo, la tesis de Zubiri no aboca a ningún panteísmo, pues la alteridad que Dios pone no se inscribe dentro de un proceso lógico que la abarque. Dios, al crear, pone una alteridad radical, que ningún proceso lógico puede "superar" o anular, porque Dios no es formalmente logos, y el logos humano es radicalmente derivado y línito. Dios no puede, por tanto, ser idéntico a la creación.

Además, la posición de alteridad no implica ninguna alteración de su realidad en virtud de algún tipo de emanación. Tal vez Zubiri no esté tan lejos de la concepciớn de Molumann según la cual la "creación de la nada" significa en última instancia que Dios, al crear, se retira haciendo un lugar a has criaturas's . Sin embargo, lo que en Moltmann es una explicación con categorias espaciales y molivada últimamente por intereses ecológicos, en Zubiri es una estricta tesis metalísica que en definitiva quiere responder a un problema radical: el de la liberación de la teologia cristiana de los moldes clásicos del pensamiento europeo. No se trata de poner un espacio, sino la alteridad de lo real en lanto que real. No se trata de retirarse, sino de poner en la realidad aquello que no es Dios. Es la creación vista fuera del horizonte de la creación.

\section{Conclusión}

Con esto no hemos agotado los problemas teológicos tratados por Zubiri. Pero al menos queda caracterizado, a grandes rasgos, el sentido fundamental de sus trabajos en el campo de la teología. Zubiri no ha pretendido en primera línea elaborar una teología, si con ello se entiende una formulación sistemática del mensaje cristiano. Ciertamente, hay en Zubiri el esbozo de una teologia y los materiales fundamentales para su elaboración. Pero no es éste el núcleo de sus trabajos teológicos. Sin embargo, sería demasiado poco decir que Zubiri ha querido simplemente aplicar a la teología determinados conceptos de su filosofía, o interpretar determinados contenidos fundamentales del cristianismo a una luz nueva. Lo más radical de la reflexión de Zubiri ha sido liberar a la teología tanto del horizonte intelectual que ella misma creó -el horizonte de la nihilidad - como de un cúmulo de presupuestos inveterados que gravitan sobre la filosofía desde el tiempo de los griegos.

El intento de Zubiri se distingue así de toda vana apología del cristianismo (cfr. HR 12, 193). Como Zubiri señala, los apologetas no suelen hacer avanzar un adarme ningún tema apologetizado (cfr. HR 193). Ahora vemos por qué: las apologías suelen presuponer, o bien un horizonte intelectual pasado, o bien un horizonte presente al que se trata de traducir el mensaje cristiano. El intento de Zubiri se distingue de loda apología porque, antes de toda "traducción" o de todo mantenimiento de un lenguaje determinado, ha cuestionado radicalmente los presupuestos filosóficos sobre los que las apologías en sentido clásico se fundan. Por eso, más que de apología habría que hablar de una apólysis (liberación, 
absolución). Zubiri decla de la fenomenologla que el gran mérito de ésta fue el crear un ámbito donde filosofar libremente (cfr. FM 17s). Tal vez la aportación fundamental de las reflexiones teológicas de Zubiri sea justamente la de haber creado un ámbito donde hacer teología libremente. La teología, lejos de estar ligada a los horizontes clásicos del pensamiento europeo, es posible en un contexto no sólo post-moderno, sino ante todo post-hegeliano y por ello post-europeo.

\section{Notas}

1. En este đabajo los escritos de Xavier Zubiri se citarán según el siguiente sistema de siglas:

CLF: Cinco lecciones de filosofla, $3^{3}$ ed., Madrid, 1980.

DHC: "Dios, hombre, Cristianismo," volumen inédito de escritos teológicos.

EDR: Estruclura dinámica de la realidad, Madrid, 1989.

EFM: "El fundamento del mundo", texto inédito.

FM: "Filosofía y metafisica", en Cruz y Raya, núm. 30 (1935), pp. 7-60.

HD: El hombre y Dios, Madrid, 1984.

HR: El problema filosófico de la historia de las religiones, Madrid, 1993.

IL: Inseligencia y logos, Madrid, 1982.

IRA: Inseligencia y razb́n, Madid, 1983.

IRE: Inseligencia sentiense. Inseligencia y realidad, 31 ed., Madrid, 1984.

NHD: Naturaleza, historia, Dios, 9' ed., Madrid, 1987.

RTE: "Reflexiones teológicas sobre la eucaristía", Estudios eclesiásticos, vol. 56, núm. 216-217. Bilbao (1981) pp. 41 -59.

SE: Sobre la esencia, 5" ed., Madrid, 1985.

SH: Sobre el hombre, Madrid, 1986.

SPF: "Sobre el problema de la filosolía", I: en Revissa de Occidense, núm. 115 (1933), pp. 51-80; I: en Revista de Occidente, núm. 118 (1933), pp. 83-117.

SSV: Sobre el sentimienso y la volición. Madrid, 1992.

2. Sobre el carácter "postniezzscheano" de la filosofía de Zubiri cfr. J. Conill, El crepúsculo de la metafLsica, Barcelona, 1988, pp. 236ss.

3. Cfr. G. von Rad, Theologie des Alten Testaments, vol. I, 1957, pp. 146s.

4. Mem. I, 2, 3, citado por W. Panneberg. Systematische Theologie, vol. 2, Gotinga, 1991, p. 28r.

5. Cfr. W. Pannenberg. "Die Aufnahme des philosophischen Gottesbegriffs als dogmatisches Problem der fruhchrisulichen Theologie", en Grundfragen systemalischer Theologie, vol. 1, Gotinga, 1967, pp. 315-316.

6. Cfr. Pastor de Hermas, Mand., 1, 1, en M. J. Rouët de Joumel, Enchiridion pairisticum, Barcelona, 1962, p. 28.

7. Cfr. Justino, "Apología I", 10, 2 en D. Ruiz Bueno, Padres apologistas griegos (s. II). Madrid, 1954, p. 190.

8. Cfr. Justino, Apología I, 59-60, en D. Ruiz Bueno, op. cit., pp. 247-249.

9. Cfr. Atenágoras, "Suppl." 22, 2, eitado por W. Pannenberg. Systematisehe Theologie, vol. 2, op. cil., p. 28. 
10. Cfr. Taciano, Discurso contra los griegas, 5, en D. Ruiz Bueno, op. cit., pp. 578-579.

11. Cfr. Tebfilo de Antioquía, Ad Ausolycum I, 4, en D. Ruiz Bueno, op. eis., pp. 785-786.

12. Cfr. Ireneo de Lyon, Adversus haereses, I, 22, 1; I, 10, 4, en M. J. Roult de Jourmel, op. cis., Pp. 82-83.

13. Cfr. Agustín de Hipona, De Genesi contra Manichaeos, I, 6, 10, en M. J. Rouèt de Jounel, op. cir., p. 534.

14. Cfr. Agustín de Hipona, De vera religione, 18, 36, en M. J. Rouët de Joumel, op. cir., p. 535.

15. Cfr. las observaciones de W. Pannenberg a la reducción unilateral de la revelación a la palabra en su Systematische Theologie, vol. 1, Gotinga, 1988, pp. 258ss.

16. Cfr. Orígenes. Peri arkhôn, I, 2, 2, citado en W. Pannenberg, Systematische Theologie, vol. 2, op. cir., p. 40n.

17. Cilado por W. Pannenberg, ibid.

18. Cfr. Agustín de Hipona, De genesi ad litteram imperfectus liber, II, 6. 12, citado en W. Pannenberg, ibid.

19. Cfr. Tomás de Aquino, Summa theologica, I, 15, 2.

20. Cfr. W. Pannenberg. Systematische Theologie, vol. 2, op. cit., pp. 40-41:

21. Cfr. Boecio, Liber de duabus naturis, cap. 3, en J. P. Migne (ed.), Patrologiae cursus completus, series latina, vol. 64, p. 1343.

22. Cfr. D. Gracia, "Persona y comunidad. De Boecio a Santo Tomás de Aquino", Cuadernos salmantinas de filosofla, núm. 11 (1984), p. 69.

23. Cfr. Agustin de Hipona, De Trinitate, XV, 22, 42.

24. Cfr. Tomás de Aquino, / Sert. d. 26 q. 2 a. 2 ad. 2.

25. Cfr. K. Rahner, "Der dreifaltige Goll als transzendenter Urgrund der Heilsgeschichte", en Mysterium Salutis, vol. 2, Einsiedeln, 1967, pp. 317-401.

26. Cfr. K. Barth, Kirchliche Dogmatik, vol. 1, t. 1, Zuirich, 1964 (6' ed.), pp. 323 ss.

27. Cfr. K. Rahner, ibid., p. 391.

28. Cfr. W. Pannenberg, Systematische Theologie, vol. 1, op. cit., pp. 329-335.

29. Rahner, tras haber desplazado el sentido de la barthiana Selbstmilseilung desde la "autorrevelación" a la "autodonación", en el caso de la muerte de Jesús ya no nos habla de Selbstmittelilung sino de Selbstaussage, cfr. K. Rahner, Grundkurs des Glaubens, Einfuhrung in den Begriff des Christetums, Friburgo, 1989, p. 298.

30. Es la crítica de $L$. Feverbach al concepto cristiano de la divinidad, $c f r$. Das Wesen des Christentums, Berlín, 1956, vol. 1, pp. 106s.

31. Cfr. J. Moltmann, Trinirät und Reich Gottes. Zur Gotteslehre. Munich, 1980, pp. 166ss, $193 \mathrm{~s}$.

32. Cfr. W. Pannenberg, Anthropologie in theologischer Perspektive, Gotinga, 1983, pp. 215-216, 513-514; Systematische Theologie, vol. 1. op. eit, p. 347.

33. Cfr. W. Pannenberg. Systemarische Theologie, vol. 1 op. cit., Pp. $415,463$.

34. H. Mulhlen niega que el Espíritu Santo tenga carácter personal en sentido estricto justamente porque no aparece en la escritura como un "yo" subjetual, cfr. Der Heilige Geist als Person, Munich, 1963.

35. Cfr. W. Pannenberg. Systematische Theologie, vol. 2, op. cit., p. 27.

36. Cfr. W. Pannenberg, Systematische Theologie, vol. 2, pp. 40-41.

37. Cfr. la teología fundamental de P. Kлauer, Der Glaube komms vom Hören. Ökume- 
nische Fundamentalheologie, Friburgo, 1991.

38. Cfr. E. Jüngel, "Gott als Geheimnis der Welt", Zur Begrïndung der Theologie des Gelouzigten in Streit zwischen Theismus und Atheismus, Sa ed., Tubinge, 1986, p. 338.

39. Cfr. E. Jingel, ibid., p. 483.

40. Cfr. E. Jingel, ibid., p. 312.

41. Cfr. E. Jungel, ibid, p. 290.

42. Sobre este problema puede verse mi trabajo "La historia como revelación de Dios según Pamenberg. Reflexión ctílica", en la Revista Latinoamericana de Teologla, núm. 25 (1992) pp. 59-81.

43. Cfr. J. Sobrino, "Significado de Jesús histórico en la cristología latinoamericana", en Jesús en América Latina. Su significado para la fe y para la cristologla, Santander, 1982, p. 115.

44. De hecho, las distinciones entre Trinidad economica $e$ inmanente parten de una reducción de la coonomía a la revelación. Naruralmente, la Trinidad en sí misma es siempre mayor que la Trinidad revelada, dados los límites de la inteligencia humara. Pero la Trinidad que salva y la Trinidad que deiforma (y en esto consiste últimamente la economfa) son formalmente idénticas a la Trinidad inmanente, y no pueden ser otra.

45. Cfr. W. Parmenberg, "Die Aufnahme des philosophischen Gottesbegriffs als dogmatisches Problem der fruhchristlichen Theologie", op. cir., Pp. 304-305.

46. Cfr. J. Moltunann, Trinisät und Reich Gottes, op. cì., p. 189.

47. A diferencia de to que piensa P. Knauer, Der Glaube komm vom Hören, op. cit., pp. 43ss.

48. Cfr. K. Barth, Kirchliche Dogmatit, op. cit., vol. III/3, p. 327. citado en W. Pannenberg, Systematische Theologie, vol. 2, op. cit., p. 29.

49. Cfr. W. Pannenberg, Systematische Theologie, vol. 2, op. cit., p. 29.

50. Cfr. Como dice Zubiri, "el Dios de las religiones es el Dios a que fllosoficamente se llega siempre que la filosolía no se acantone en nociones griegas" (HD 152).

51. Cfr. G. W. F. Hegel, Philasophie der Religion, II, en sus Werke, Francfort, 1986, vol. 17, pp. 239.

52. Cfr. W. Pannenberg. Systemalische Theologie, vol. 2, op. cis., p. 43.

53. Cfr. W. Pannenberg, Systematische Theologie, vol. 2 op. cit., p. 29. 